\begin{tabular}{|c|c|c|}
\hline & $\begin{array}{l}\text { International Journal of Environment, Agriculture and Biotechnology } \\
\text { Vol-6, Issue-1; Jan-Feb, } 2021\end{array}$ & $(8 \longdiv { = }$ \\
\hline DEAB & $\begin{array}{c}\text { Journal Home Page Available: https://ijeab.com/ } \\
\text { Journal DOI: 10.22161/ijeab }\end{array}$ & \\
\hline
\end{tabular}

\title{
LED night lighting improving mini-budding technology in
}

\section{Hevea brasiliensis}

\author{
Xing-Cheng Yao, Han-Qi Tu, Xin-Long Wang, Jun Wang*
}

Rubber Research Institute, Key Laboratory of Biology and Genetic Resources of Rubber Tree, Chinese Academy of Tropical Agricultural Sciences, Haikou, 571101, Hainan, China

*Corresponding author

Received: 27 Nov 2020; Received in revised form: 12 Jan 2021; Accepted: 21 Jan 2021; Available online: 01 Feb 2021

(C)2021 The Author(s). Published by Infogain Publication. This is an open access article under the CC BY license (https://creativecommons.org/licenses/by/4.0/).

\begin{abstract}
Mini-budding, exploiting seedlings of about 20 days, is a major technology for planting material propagation of rubber tree in China. The first pair leaves should be kept on rootstocks for assimilation. Manually axillary bud picking is needed to promote scion bud germination, but it is difficult and labor intensive. In this study, topping was carried out on the position below the first pair leaves and the subsequent plants were subjected to LED night lighting. The plant growth and the plant survival rate were improved by night lighting. The scion growth of the $1^{\text {st }}$ flush was not comparable to that of plants with leaves on rootstocks. The high amount of chlorophyll content in the leaf might be response for this. The plant survival rate of the treatment was similar with that of plants with leaves on rootstocks. Thus, applying LED night lighting to the plants without leaves on rootstocks improved mini-budding technology by avoiding axillary bud picking.
\end{abstract}

Keywords - grafting, nursery, photoperiod, vegetative propagation, rubber tree.

\section{INTRODUCTION}

The Para rubber tree (Hevea brasiliensis Willd. Ex. A. de. Juss.Müll-Arg.) is preferred over alternative sources of natural rubber worldwide due to the quality and quantity of latex produced. The planting materials of rubber trees are vegetatively propagated by bud grafting (budding is the colloquial term). The combined plants include clonal scions and hetero-rootstocks. After grafted, the rootstock can affect the initiated growth of scion. The carbohydrate for germination of grafted bud (scion) is directly provided by the rootstock. The leaves of germinating shoots could not assimilate until at the stage of mid light green period
(Dong et al., 1986).Therefore, the early growth of grafted shoot is mainly controlled by the rootstock. In general, the larger size of rootstock, the more carbohydrate stored in the rootstock, and the stronger of germinating shoot.

There are several types of bud grafting according to the size of rootstocks (Priyadashan, 2017). Mini-budding(Figure 1), developed in the 1980s in China by Huang (Huang, 1989), is carried out when the seedling rootstocks are as young as 2-3 weeks old. The diameter and height of seedling rootstock (graft position) is less than $5 \mathrm{~mm}$ and $30 \mathrm{~cm}$, respectively. One month after grafting, topping is carried out on the position just above 
the first pair leaves. The axillary buds above the grafted bud are removed to eliminate apical dominance. Using mini-budding, planting materials could be produced as fast as 6 months after sowing seeds in the seedbed during August-September. Mini-budding is preferred in China because it reduces cost of production by decreasing the time and nursery area for production of grafted planting materials.

As the rootstocks for mini-budding are quite small and could not supply sufficient carbohydrate for the shoot (scion) grow, at least one or two leaves must be kept on the grafted root stocks for assimilation (Figure 1-C). However, manually axillary budpicking is difficult and labor intensive. Axillary bud picking is practiced twice or thrice sometimesbefore axillary buds are totally picked. Therefore, it is necessary to improve topping and subsequent axillary bud picking for mini-budding plants.
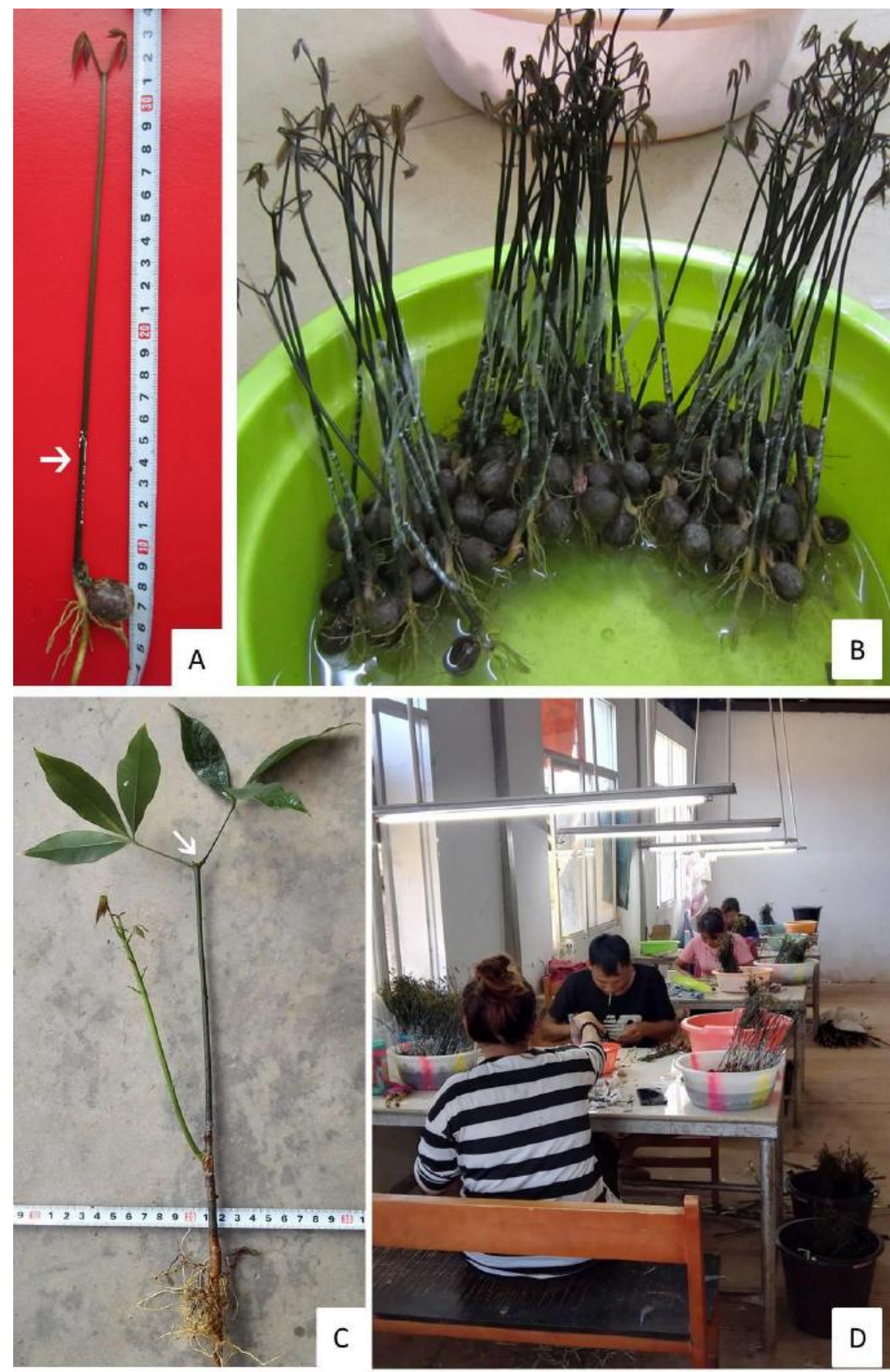

Fig. 1: Mini-budding profile. (A),Seedlings suitable for mini-budding. Arrow: graft position. (B),Graft finished. (C), Scion shoot germination. Arrow: axially buds have been picked. (D), Grafting in a room. 
Light is a key environmental factor regulating plant growth by affecting photosynthesis. Extended photoperiod can improve plant growth by synthesizing more carbohydrate. Supplemental lighting during the night extends the photoperiod and thus promotes plant growth. Light-emitting diode (LED) lamps are the preferred source for supplemental lighting due to their low operating temperature, durability and low cost (Singh et al., 2015). Supplemental night lighting has been widely used in the production of crops and other plants to promote growth (Fukuda et al. 2000, 2004; Okushima et al., 2012; Zhou et al., 2013; Kweon et al., 2016; Tewolde et al., 2016).

In this study, the min-budding rootstock plants were cut off on the position just below the first pair leaves (the first flush) when the plants grew to the stationary phase of the second flush. The grafted plants were then subjected to overnight LED lighting. The effect of LED night lighting on the growth of mini-budding plants was investigated.

\section{MATERIALS AND METHODS}

\section{Plant materials}

Hevea seeds of clone GT1 were sowed in August, 2019. Mini-budding was carried out with scion clone CATAS 7-33-97 in September. The grafted plants were planted in polybags which were placed in an arched shed with sun shade cloth. Topping was carried out in November, 2019, when the grafted rootstock plants grew to the second flush.

The grafted plants were cut off on the position just below the first pair leaves. Two treatments were carried out and each replicated thrice. Treatment one (designated as I-LED) was subjected to LED lamp night lighting. LEDs were hung $0.5 \mathrm{~m}$ above the plants. The lamp spectrum was red and blue combined with a photosynthetic photon flux density (PPFD) of $200 \mu \mathrm{mol}$ $\mathrm{m}^{-2} \mathrm{~s}^{-1}$ measured at $10 \mathrm{~cm}$ from the LED lamp. Supplemental lighting was applied during the night from 19:00 to 06:00.Treatment two (designated as II - no LED) was subjected to no LED night lighting. The plants obtained by conventional mini-budding were used as a control.

\section{Plant growth measurements}

The plant height and stem (scion) diameter were monitored in May, July, September and November, 2020. The flush number and flush length were measured when the experiment was finished in November, 2020. The stem diameter was measured at $5 \mathrm{~cm}$ above the shoot germinating position. The percentage of plant survival (scion shoots that successfully grew to the stationary phase of second flush) was calculated.

\section{Chlorophyll content analysis}

After cutting off, the green bark of the rootstock stems was analyzed for chlorophyll content. The green bark was peeled from the stems and the fresh weight of bark was measured. Approximately $0.1 \mathrm{~g}$ of bark tissue was ground and incubated in $20 \mathrm{ml}$ of a mixture of acetone, ethanol and deionized water $(4.5: 4.5: 1)$ in the dark for $24 \mathrm{~h}$ at $25^{\circ} \mathrm{C}$. The absorptions of chlorophyll a andchlorophyll $\mathrm{b}$ were measured at 647 and $664 \mathrm{~nm}$, respectively, using a spectrophotometer (TU-1810s, PERSEE, China). The chlorophyll content was calculated according to the methods of Wellburn(1994).The total amount of chlorophyll of green bark was calculated as chlorophyll content multiplying fresh weight. The chlorophyll content of the first pair leaves kept on the rootstock was also analyzed. The fresh weight of the two trifoliate leaves (without petioles) was measured. The total amount of chlorophyll of leaf was calculated as chlorophyll content multiplying fresh weight.

\section{Statistics analysis}

The statistical analyses were performed using SPSS 22.0 software. Significance at the 0.05 level was determined using Tukey's multiple range test.

\section{RESULTS AND DISCUSSION}

The diameter of seedling rootstocks was measured when mini-budding was carried out. The mean diameter was $3.51 \mathrm{~mm}$ at the position of $3 \mathrm{~cm}$ above the root collar. After cutting off on the position below the first pair leaves, the grafted plants were grown under the condition with or without supplemental LED night lighting. The plant height and stem diameter were monitored after growing 6 , 8, 10 and 12 months. The plants of I- LED exhibited larger 
stem diameter and higher plant height than II- no LED (Figure 2, 3), showing that supplemental LED night lighting promoted plant growth.The plants of I- LED grew more flushes (mean 5.5) than that of II- no LED (mean 4.6), which indicated that the rhythmic growth has been accelerated. The mean flush length of plants of I- LED was significantly longer than that of II- no LED (Figure 4). The 1st,2nd, 3rd, 4th and 5th flush length between I- LED and II- no LED were compared, respectively. The 3rd flush length of I- LED was significantly longer than that of II- no LED, but the other flushes showed similar flush length (figure 4). The 1st flush length of control plants (obtained from conventional mini-budding)was $14.35 \mathrm{~cm}$, significantly longer than that of I- LED $(6.67 \mathrm{~cm})$ and IIno LED $(5.43 \mathrm{~cm})$. The stem diameter of control plants was also larger than that of I- LED when the shoots finished the first flush growth.This indicated that more carbohydrate has been assimilated by plants with leaves kept on rootstocks. Even though the grafted plants without leaves grew under night lighting, the carbohydrate they assimilated was not comparable to that assimilated by the leaves in control plants.

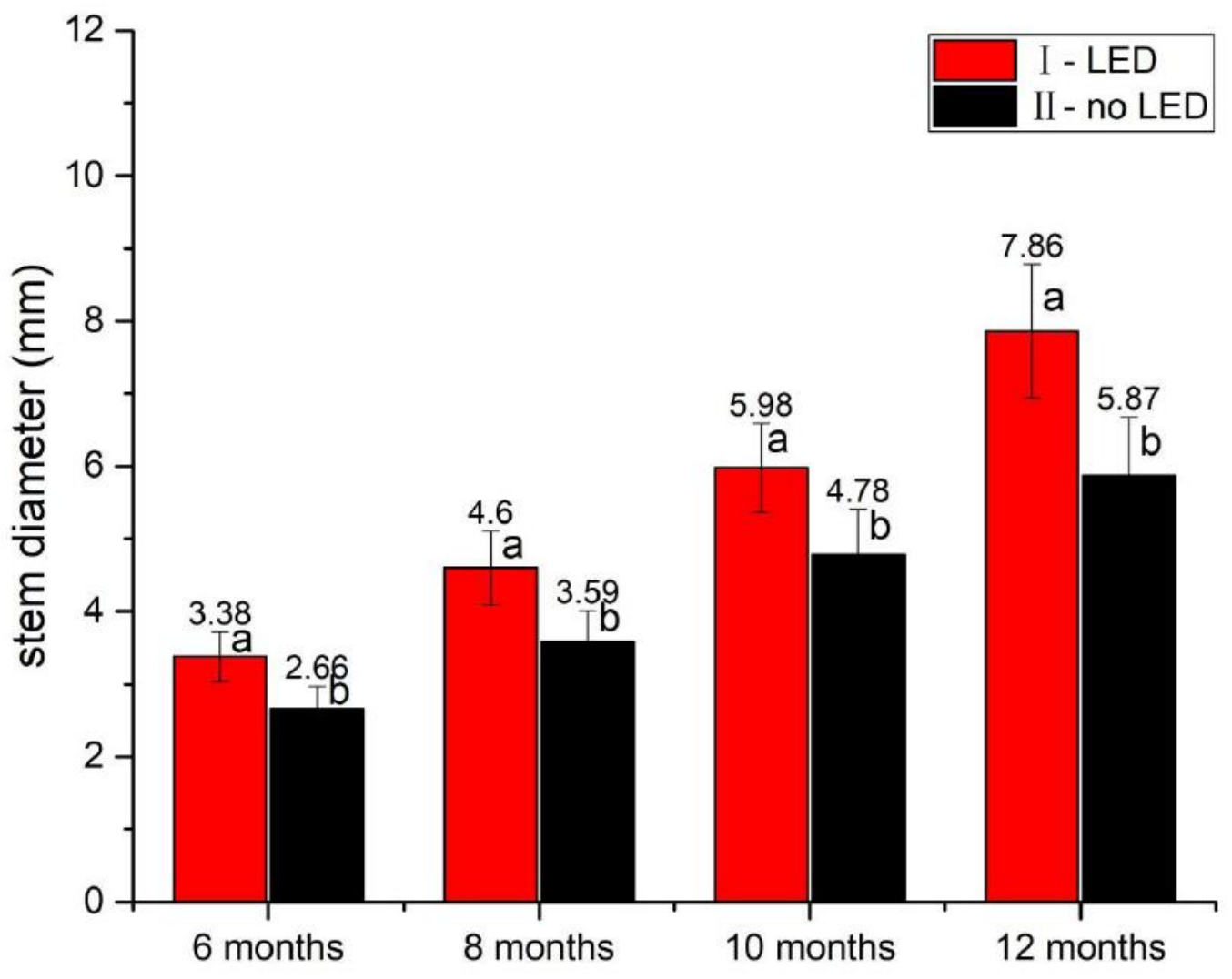

Fig. 2: Comparison of stem diameter between I- LED and II- no LED. 


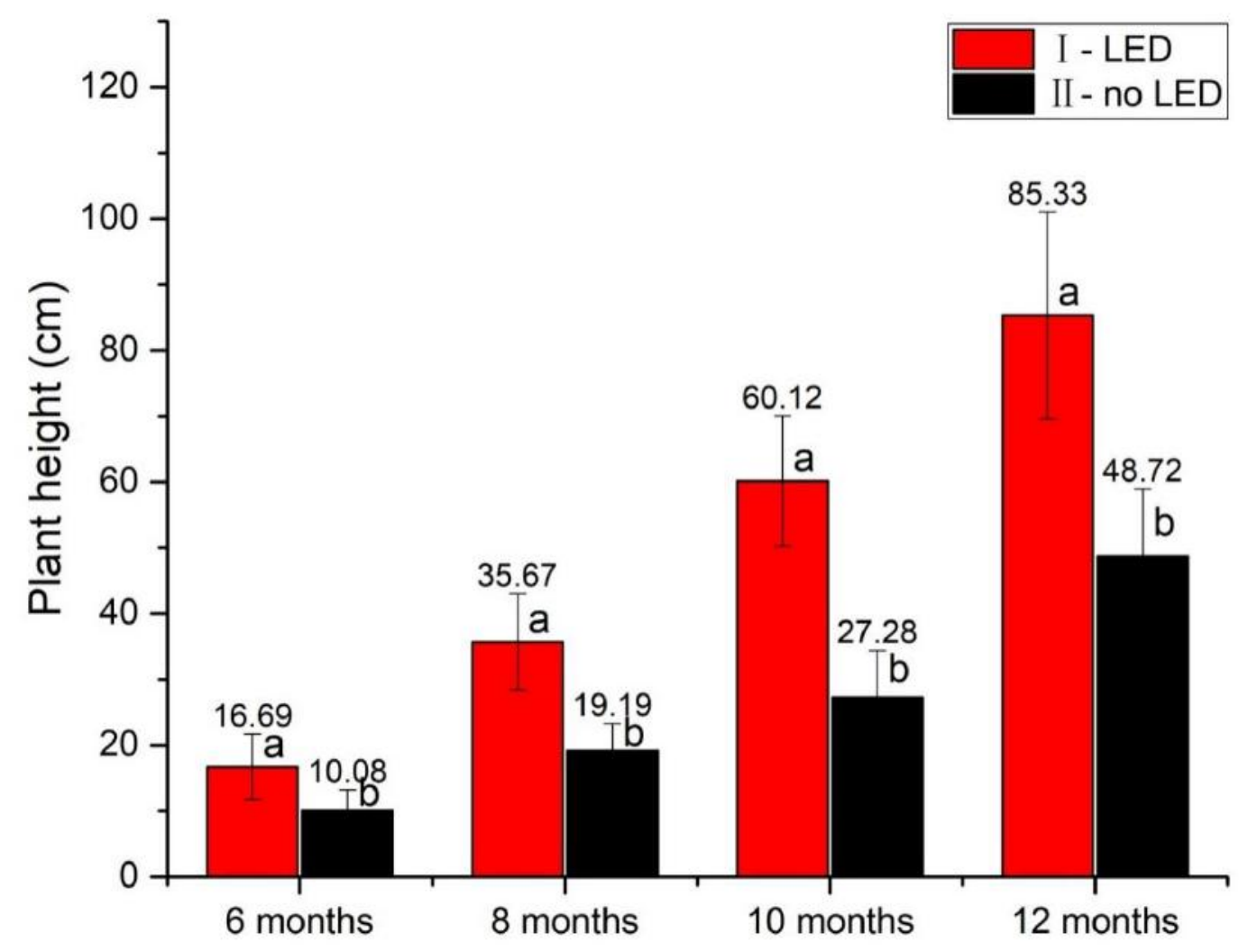

Fig. 3: Comparison of plant height between I- LED and II- no LED.

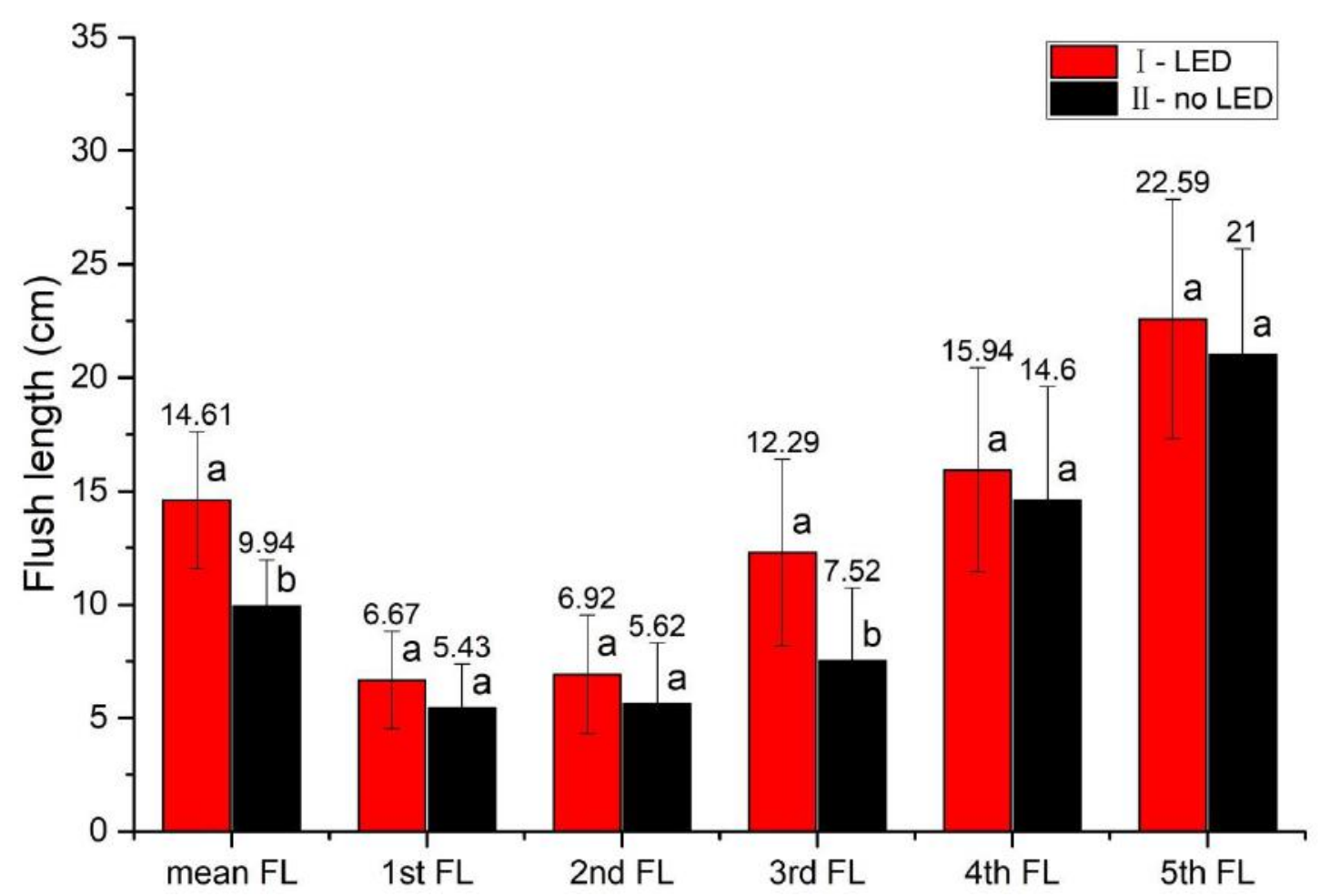

Fig. 4: Comparison of flush length (FL) between I-LED and II-no LED. The earliest germinated flush was designated as the first flush. 
The plant survival rate is an important index for evaluating seedling cultivation technology because it affects the production cost. The plant survival rate of ILED and II- no LED was $92.3 \%$ and $45.4 \%$, respectively. There was significant difference between I- LED and IIno LED. This implied that the plants of I- LED could assimilate during night lighting. Therefore, more carbohydrate had been synthesized, which was then utilized for shoot growth. The percentage of plant survival of I- LED (92.3\%) was comparable with that of control plants $(93.4 \%)$.This indicated thatthe mini-budding plants without leaves on rootstock could provide proper carbohydrate for normal shoot growth when grew under supplemental LED night lighting.

The chlorophyll content in the green bark tissue of young rootstock was $1.77 \mathrm{mg} \mathrm{g}^{-1} \mathrm{FW}$ (fresh weight), which suggested that the green bark could photosynthesize. The chlorophyll content in the leaves was much higher (3.62 $\left.\mathrm{mg} \mathrm{g}^{-1} \mathrm{FW}\right)$. The fresh weight of leaf was 3 times of that of green bark. The total chlorophyll amount in the bark tissue and the leaves was 0.97 and $5.86 \mathrm{mg}$ per plant, respectively. The total chlorophyll amount in the leaves was about 6times of that in the bark tissue. Therefore, the plants with leaves on rootstock can assimilate much more carbohydrate than plants ofI- LED during daytime. According to Wang et al (2010)the net photosynthetic rate of CATAS 7-33-97 under PPFD $200 \mu \mathrm{mol} \mathrm{m} \mathrm{m}^{-2} \mathrm{~s}^{-1}$ was about $3 \sim 5 \mu \mathrm{mol} \mathrm{m} \mathrm{m}^{-2} \mathrm{~s}^{-1}$, and the dark respiration rate was about $1.75 \mu \mathrm{mol} \mathrm{m} \mathrm{m}^{-2} \mathrm{~s}^{-1}$. It indicated that the amount of carbohydrate of I - LED synthesized during night lighting could not compensate for the carbohydrate gap during daytime between I- LED and control plants. This probably was thereason why control plants were stronger than plants of I- LED.

The size of mini-budding plants is smaller, compared to that of green and brown budding. The plant density of mini-budding plants without leaves on rootstocks during night lighting period wouldbe greater. Therefore, applying LED night lighting will not cost too much for power energy. Axillary bud picking is labor intensive and the mean time is 45 second per one plant. However, topping with a scissor on the position below the first pair leaves only spends 1 second per plant. There is no procedure of axillary bud picking. Therefore, the labor cost will reduce ISSN: 2456-1878 greatly.

\section{CONCLUSION}

Mini-budding is a prevalent technology for vegetative propagation of rubber tree in China. The first pair leaves should be kept on rootstocks for assimilation when topping is conducted, but the axillary bud picking which is labor intensive must be carried out. Mini-budding plants without leaves on the rootstock exhibited extremely poor growth and low plant survival rate. LED night lighting could improve the growth as well as plant survival rate of mini-budding plants without leaves on the rootstock. Therefore, applying LED night lighting to the mini-budding plants without leaves on the rootstock improved mini-budding technology by avoiding axillary bud picking.

\section{ACKNOWLEDGEMENT}

The study was financially supported by China Agriculture Research System (CARS-33-YZ4).

\section{REFERENCES}

[1] Dong, J. H, Li, D., He, C., Shen, Q., Tang, Y. (1986). Relation of glycollate oxidase activity to photosynthesis activity and chlorophyll content in leaves of Hevea brasiliensis. Chinese Journalof Tropical Crops, 7(1): 1-8.

[2] Fukuda, N., Nishimura, S.,Fumiki, Y. (2004). Effect supplemental lighting during the period from middle of night to morning on photosynthesis and leaf thickness of lettuce (Lactuca sativa L.) and tsukena (Brassica campestris L.). Acta Hortic, 633: 237-244.

[3] Fukuda, N., Suzuki, V., Ikeda, H. (2000). Effects of supplemental lighting from 23:00 to 7:00 on growth of vegetables cultured by NFT. J Japan Soc Hort Sci, 69: $76-83$.

[4] Huang, S. F.(1989). A novel approach to rubber propagation-mini-seedling budding. Chinese Journal of Tropical Crops, 10(1): 25-31.

[5] Kweon, H. J., Park, M. Y., Song, Y. Y., Kang, S. B., Sagong, D. H. (2016). Influence of red LED treatment on photosynthesis, vegetative growth and fruit quality in'Fuji'/M 26 apple trees during night. Protected 
Horticulture and Plant Factory, 25: 57-6.

[6] Okushima, L., Fukuda, N., Kanesaka, N., Sekiguchi, K., Odawara, N., Sase, S, Mito, C. (2012) Effect of overnight supplemental lighting with different spectral LEDs on the growth of some leafy vegetables. In VII International Symposium on Light in Horticultural Systems, 956:327-333.

[7] Priyadarshan, P. M. (2017). Biology of hevea rubber. Springer, Switzerland.

[8] Singh, D., Basu, C., Meinhardt-Wollweber, M., Roth, B. (2015). LEDs for energy efficient greenhouse lighting. Renewable Sustainable Energy Reviews, 49:39-147.

[9] Tewolde, F. T., Lu, N., Shiina, K., Maruo, T., Takagaki, M., Kozai, T., Yamori, W. (2016). Nighttime supplemental LED inter-lighting improves growth and yield of single-Truss tomatoes by enhancing photosynthesis in both winter and summer. Frontier Plant Sciences, 7:448.

[10] Wang, J. K., Xie, G. S., Chen, B. Q. (2010). Photosynthetic characteristics of different varieties of rubber budding trees. Southwest China Journal of Agricultural Sciences, 23(6):1882-1886.

[11] Wellburn, A. R. (1994) The spectral determination of chlorophylls a and $\mathrm{b}$, as well as carotenoids, using various solvents with spectrophotometers of different resolution. Journal Plant Physiology, 144(3):307-313.

[12] Zhou, W. L., Liu, W. K., Yang, Q. C. (2013). Reducing nitrate content in lettuce by pre-harvest continuous light delivered by red and blue light-emitting diodes. Journal Plant Nutrition, 36:481-490. 